\title{
(2) OPEN ACCESS \\ Nationwide seroprevalence of SARS-CoV-2 and identification of risk factors in the general population of the Netherlands during the first epidemic wave
}

\author{
Eric R A Vos (1), Gerco den Hartog (1D, Rutger M Schepp, Patricia Kaaijk, \\ Jeffrey van Vliet, Kina Helm, Gaby Smits, Alienke Wijmenga-Monsuur, \\ Janneke D M Verberk, Michiel van Boven, Rob S van Binnendijk, Hester E de Melker, \\ Liesbeth Mollema, Fiona R M van der Klis
}

- Supplemental material is published online only. To view please visit the journal online (http://dx.doi.org/10.1136/ jech-2020-215678).

Centre for Infectious Disease Control, RIVM, Bilthoven, Netherlands

\section{Correspondence to}

Fiona R M van der Klis Centre for Infectious Disease Control, RIVM, Bilthoven, Netherlands; fiona.van.der.klis@rivm.nl

Received 24 September 2020 Revised 3 November 2020 Accepted 10 November 2020 Published Online First 28 November 2020

\section{Check for updates}

(c) Author(s) (or their employer(s)) 2021. Re-use permitted under CC BY-NC. No commercial re-use. See rights and permissions. Published by BMJ.

\section{To cite: Vos ERA,} den Hartog G, Schepp RM, et al. J Epidemiol Community Health 2021:75:489-495.

\section{ABSTRACT}

Background We aimed to detect SARS-CoV-2 serum antibodies in the general population of the Netherlands and identify risk factors for seropositivity amidst the first COVID-19 epidemic wave.

Methods Participants ( $n=3207$, aged 2-90 years), enrolled from a previously established nationwide serosurveillance study, provided a self-collected fingerstick blood sample and completed a questionnaire (median inclusion date 3 April 2020). IgG antibodies targeted against the spike S1-protein of SARS-CoV-2 were quantified using a validated multiplex-

immunoassay. Seroprevalence was estimated controlling for survey design, individual pre-pandemic concentration, and test performance. Random-effects logistic regression identified risk factors for seropositivity.

Results Overall seroprevalence in the Netherlands was $2.8 \%(95 \% \mathrm{Cl} 2.1$ to 3.7), with no differences between sexes or ethnic background, and regionally ranging between 1.3 and $4.0 \%$. Estimates were highest among $18-39$ year-olds $(4.9 \%)$, and lowest in children 2-17 years (1.7\%). Multivariable analysis revealed that persons taking immunosuppressants and those from the Orthodox-Reformed Protestant community had over four times higher odds of being seropositive compared to others. Anosmia/ageusia was the most discriminative symptom between seropositive (53\%) and seronegative persons $(4 \%, p<0.0001)$. Antibody concentrations in seropositive persons were significantly higher in those with fever or dyspnoea in contrast to those without ( $p=0.01$ and $p=0.04$, respectively).

Conclusions In the midst of the first epidemic wave, $2.8 \%$ of the Dutch population was estimated to be infected with SARS-CoV-2, that is, 30 times higher than reported. This study identified independent groups with increased odds for seropositivity that may require specific surveillance measures to guide future protective interventions internationally, including vaccination once available.

\section{INTRODUCTION}

Severe acute respiratory syndrome coronavirus 2 (SARS-CoV-2), causative agent of coronavirus disease (COVID-19), emerged in Wuhan, China, in late 2019. On 11 March 2020, the World Health Organization (WHO) declared COVID-19 a pandemic, with over 10 million confirmed cases as of the beginning of July 2020. ${ }^{12}$ The first patient in the Netherlands was confirmed on
27 February 2020. ${ }^{3}$ Cases primarily clustered in the southeastern part of the country, but were reported in other regions quickly hereafter. Multipronged interventions to suppress the spread of the virus, including social distancing, school and bar/restaurant closure, and stringent advice to home quarantine when feeling ill and work from home, were implemented on 16 March 2020and were relaxed gradually since 1 June 2020 By 1 July 2020, 50273 cases, 11877 hospitalisations, and 6113 related deaths were reported in the Netherlands. ${ }^{3}$

Reported COVID-19 cases worldwide are an underestimation of the true magnitude of the pandemic. The scope of undetected cases remains largely unknown due to difference in restrictive testing policy and registration across countries, and occurrence of asymptomatic infections. ${ }^{4} 5$ Large-scale nationwide serosurveillance studies measuring SARS-CoV-2-specific serum antibodies could help to better assess the number of infections, viral spread, and groups at risk of infection in the general population by incorporating extensive questionnaire data, for example, on lifestyle, behaviour and profession. This might yield different factors than those identified for (severely-ill) clinical cases investigated more frequently up until now. ${ }^{6}$ Unfortunately, such nationwide studies (eg, in Spain ${ }^{8}$ and Iceland, ${ }^{9}$ ) also referred to as Unity Studies by the $\mathrm{WHO},{ }^{10}$ are scarce and mainly set up through convenience sampling.

Therefore, a nationwide serosurveillance study (PIENTER-Corona, PICO) was initiated quickly after the lockdown was in effect. This cohort is unique as it comprises data available from a previous serosurvey established in 2016/17 (PIENTER-3) of a randomised nationwide sample of Dutch citizens, across all ages and a separate sample enriched for Orthodox-Reformed Protestants, whom might have been exposed to SARS-CoV-2 more frequently due to their socio-geographicalclustered lifestyle. ${ }^{11} 12$ The presented serological framework and findings of our first round of inclusion can support public health policy in the Netherlands as well as internationally.

\section{METHODS \\ Study design}

In 2016/17, the National Institute for Public Health and the Environment of the Netherlands (RIVM) 
initiated a large-scale nationwide serosurveillance study (PIENTER-3) ( $\mathrm{n}=7600$; age-range $0-89$ years). The primary aim was to obtain insights into the protection against vaccinepreventable diseases offered by the National Immunisation Programme in the Netherlands. A comprehensive description of PIENTER-3 has been published previously. ${ }^{13}$ Briefly, participants were selected via a two-stage cluster design, comprising 40 municipalities in five regions nationwide (henceforth 'national sample', NS), and nine municipalities in the low vaccination coverage municipalities (LVC), inhabited by a relative large proportion of Orthodox-Reformed Protestants (figure 1). Among other materials, sera and questionnaire data had been collected from all participants. Hence, the PIENTER-3 study acted as baseline sample of the Dutch population for the present cross-sectional PICO-study since 6102 participants (80\%) consented to be approached for follow-up (after updating addresses and screening of possible deaths). The study was powered to estimate an overall seroprevalence with a precision of at least $2.5 \% .{ }^{13}$ The PICO-study protocol was approved by the Medical Ethics Committee MEC-U, the Netherlands (Clinical Trial Registration NTR8473), and conformed to the principles embodied in the Declaration of Helsinki.

\section{Study population and materials}

On 25 March 2020, an invitation letter was sent. Invitees (agerange 2-92 years) willing to participate registered online. After enrolment, participants received an instruction letter on how to self-collect a fingerstick blood sample in a microtainer (maximum

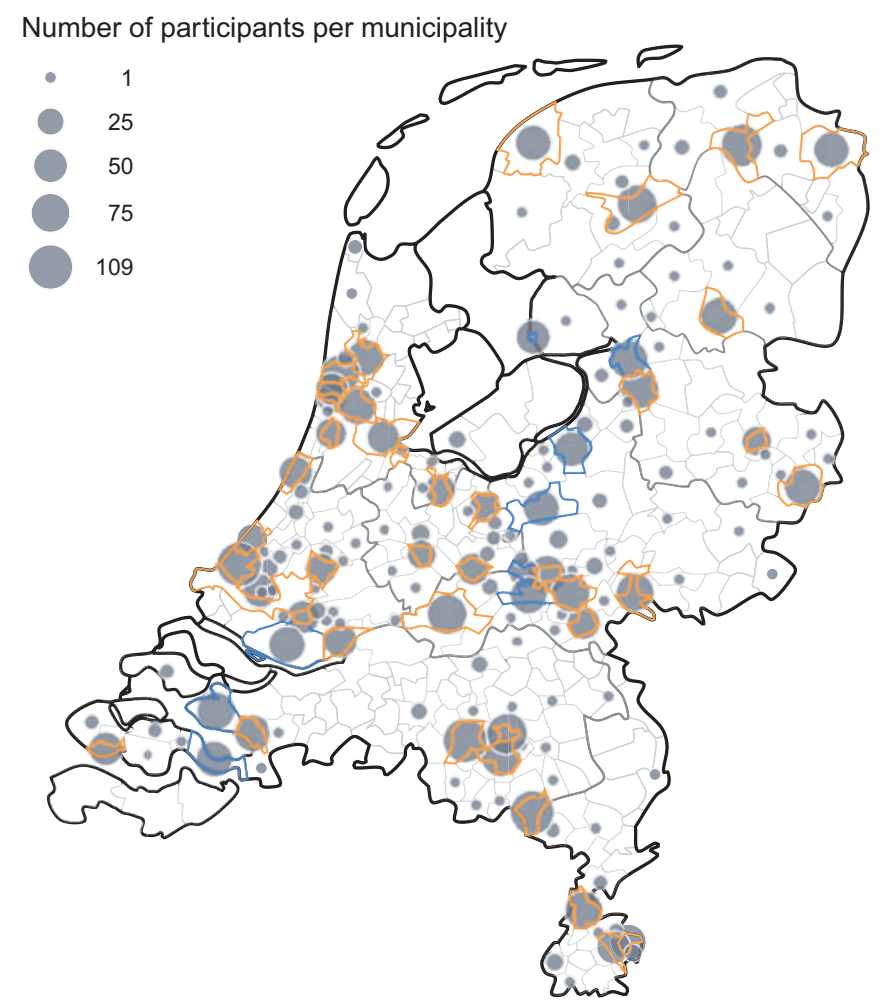

Figure 1 Geographical representation of number of participants in the PICO-study, the Netherlands, first round of inclusion, per municipality. The size of the dots reflect the absolute number of participants. Thicker grey and smaller light grey boundaries represent provinces and municipalities, respectively, and orange and blue boundaries characterise municipalities from the national and low vaccination coverage sample, respectively. of $0.3 \mathrm{~mL}$ ). Blood samples were returned to the RIVM-laboratory in safety envelopes. Serum samples were stored at $-20^{\circ} \mathrm{C}$ awaiting analyses. Materials were collected between March 31 and May 11, with the majority (80\%) in the first week of April 2020 (median collection date April 3). Simultaneous with the blood collection, participants were asked to complete an (online) questionnaire, including questions regarding sociodemographic characteristics, COVID-19-related symptoms, and potential other determinants for SARS-CoV-2 seropositivity, such as comorbidities, medication use and behavioural factors. All participants provided written informed consent.

\section{Laboratory methods}

Serum samples (diluted 1:200) were tested for the presence of SARS-CoV-2 spike S1-specific IgG antibodies using a validated fluorescent bead-based multiplex-immunoassay as described. ${ }^{14}$ A cut-off concentration for seropositivity (2.37 AU/ $\mathrm{mL}$; with specificity of $99 \%$ and sensitivity of $84.4 \%$ ) was determined by ROC-analysis of 400 pre-pandemic control samples (including a nationwide random cross-sectional sample $(n=108)$ ) as well as patients with confirmed influenza-like illnesses caused by coronaviruses and other viruses, and a selection of sera from 115 PCR-confirmed COVID-19 cases with mild, or severe disease symptoms. Seropositive PICO-samples and those with a concentration $25 \%$ below the cut-off were retested $(n=138)$, and the geometric mean concentration (GMC) was calculated. Paired pre-pandemic PIENTER-3-samples of these retested PICO-samples (available from 129/138) were tested correspondingly as described above to correct for false-positive results (online supplemental figure S1A).

\section{Statistical analyses}

Study population, COVID-19-related symptoms and antibody responses

Data management and analyses were conducted in SAS v.9.4 (SAS Institute Inc., USA) and R v.3.6. P values $<0.05$ were considered statistically significant. Sociodemographic characteristics and COVID-19-related symptoms (general, respiratory, and gastrointestinal) developed since the start of the epidemic were stratified by sample (NS vs LVC), or sex, respectively, and described for seropositive and seronegative participants. Differences were tested via Pearson's $\chi^{2}$, or Fisher's exact test if appropriate. Differences in GMC between reported symptoms in seropositive participants were determined by calculating the difference in logtransformed concentrations of those who developed symptoms at least 4 weeks prior to the sampling-ensuring a plateaued response-and tested by means of a Mann-Whitney U-test.

\section{Seroprevalence estimates}

Seroprevalence estimates (with 95\% Wilson CIs (CI)) for SARS$\mathrm{CoV}$-2-specific antibodies were calculated taking into account the survey design (ie, controlling for region and municipality) and weighted by sex, age, ethnic background and degree of urbanisation to match the distribution of the general Dutch population in both the NS and LVC sample. Estimates were corrected for test performance via the Rogan \& Gladen bias correction (with sensitivity of $84.4 \%$ and assuming a specificity of $100 \%$ after crossvalidation with pre-sera). ${ }^{15}$ Smooth age-specific seroprevalence estimates were obtained with a logistic regression in a Generalised Additive Model using penalised splines. ${ }^{16}$

\section{Risk factors for SARS-CoV-2 seropositivity}

A random-effects logistic regression model was used to identify risk factors for SARS-CoV-2 seropositivity, applying a full 
case analysis $(n=3100$; values were missing for $<5 \%$ of the participants). Potential risk factors included sociodemographic characteristics (sex, age group, region, ethnic background, Orthodox-Reformed Protestants, educational level, household size, (parent with a) contact profession, healthcare worker), and COVID-19-related factors (contact with a COVID-19 confirmed case, number of persons contacted yesterday, working from home (normally and in the last week), comorbidities (combining diabetes, history of malignancy, immunodeficiency, cardio-vascular, kidney and chronic lung disease (note: as a sensitivity analysis, comorbidities were also included separately)), and use of blood pressure medication, immunosuppressants, statins and antivirals/antibiotics in the last month). Models included a random intercept, potential clustering by municipality and region was accounted for, and odds ratios (OR) in univariable analyses were a priori adjusted for sex and age. Variables with $\mathrm{p}<0.10$ were entered in the multivariable analysis, and backward selection was performed -manually dropping variables one-by-one based on $p \geq 0.05$ - to identify significant risk factors. Adjusted ORs and corresponding 95\% CIs were provided.

\section{RESULTS}

\section{Study population}

Of 6102 invitees, 3207 (53\%) donated a serum sample and filled-out the questionnaire, of which 2637 persons from the NS and 570 from the LVC. Participants from across the country participated (figure 1), with age ranging from 2 to 90 years (table 1$)$. In the NS, slightly more women $(55 \%)$ participated, most $(88 \%)$ were of Dutch descent, nearly half had a high educational level, and $45 \%$ was religious. 20 percent of persons between age 25-66 years were healthcare workers and $56 \%$ of the (parents of) participants reported to have had daily contact with patients, clients and/or children in their profession/volunteer work normally. Over half of the participants lived in a $\geq 2$-person household, and $78 \%$ reported to have had physical contact with $<5$ people outside their own household yesterday (during lockdown), of which more than half with nobody. Comorbidities most frequently reported included chronic lung and cardiovascular disease (both 13\%), and a history of malignancy (5\%). In line with the population distribution, the LVC sample was characterised by a relative high proportion of Orthodox-Reformed Protestants from Dutch descent (table 1). Sociodemographic characteristics between responders and non-responders are provided in online supplemental table S1.

\section{COVID-19-related symptoms and antibody responses}

In total, $63 \%$ of participants reported to have had $\geq 1$ COVID-19-related symptom(s) since the start of the epidemic, with runny nose $(37 \%)$, headache $(33 \%)$, and cough (30\%) being most common (table 2). All reported symptoms were significantly higher in seropositive compared to seronegative persons, except for stomach ache. The majority of those seropositive (93\%) reported to have had symptoms ( $90 \%$ of men vs $95 \%$ of women), of whom three already in mid-February, 2 weeks prior to the official first notification. Median duration of illness in the seropositive participants was 8.5 days (IQR: $4.0-12.5), 16 \%(\mathrm{n}=12)$ visited ageneral practitioner and one was admitted to the hospital. Among seropositive persons, most reported to have had $\geq 1$ respiratory symptom(s) (86\%), with runny nose and cough (both $61 \%)$ most regularly, and $\geq 1$ general (84\%) symptom(s), of
Table 1 Sociodemographic characteristics of participants in the PICO-study and weighted seroprevalence in the general population of the Netherlands, first round of inclusion, by national sample and low vaccination coverage sample

\begin{tabular}{|c|c|c|c|c|c|c|c|c|}
\hline & \multicolumn{4}{|c|}{ National sample } & \multicolumn{4}{|c|}{$\begin{array}{l}\text { Low vaccination coverage } \\
\text { sample }\end{array}$} \\
\hline & \multicolumn{2}{|l|}{ Total } & \multicolumn{2}{|c|}{$\begin{array}{l}\text { Weighted } \\
\text { SARS-CoV-2 } \\
\text { seroprevalence }\end{array}$} & \multicolumn{2}{|c|}{ Total } & \multicolumn{2}{|c|}{$\begin{array}{l}\text { Weighted } \\
\text { SARS-CoV-2 } \\
\text { seroprevalence }\end{array}$} \\
\hline & $\mathrm{n}$ & $\%$ & $\%$ & $95 \% \mathrm{Cl}$ & $\mathrm{n}$ & $\%$ & $\%$ & $95 \% \mathrm{Cl}$ \\
\hline Overall & 2637 & 100 & 2.8 & $2.1-3.7$ & 570 & 100 & 2.9 & $1.4-6.3$ \\
\hline \multicolumn{9}{|l|}{ Sex } \\
\hline Men & 1184 & 44.9 & 2.9 & $1.8-4.5$ & 233 & 40.9 & 4.0 & $1.5-10.6$ \\
\hline Women & 1453 & 55.1 & 2.7 & $1.7-4.1$ & 337 & 59.1 & 1.9 & $0.7-4.9$ \\
\hline \multicolumn{9}{|l|}{ Age categories } \\
\hline $2-17$ & 507 & 19.2 & 1.7 & $0.6-4.9$ & 93 & 16.3 & 0.0 & NA \\
\hline $18-39$ & 735 & 27.9 & 4.9 & $3.2-7.5$ & 196 & 34.4 & 6.8 & $3.0-14.6$ \\
\hline $40-64$ & 919 & 34.8 & 1.9 & $1.2-3.2$ & 198 & 34.7 & 2.4 & $0.7-8.3$ \\
\hline $65-90$ & 476 & 18.1 & 2.5 & $1.2-5.1$ & 83 & 14.6 & 1.0 & $0.1-7.0$ \\
\hline \multicolumn{9}{|l|}{ Region } \\
\hline North & 566 & 21.5 & 1.3 & $0.4-3.2$ & NA & NA & NA & NA \\
\hline Mid-West & 427 & 16.2 & 4.0 & $1.8-8.0$ & NA & NA & NA & NA \\
\hline Mid-East & 508 & 19.3 & 3.1 & $1.3-6.2$ & NA & NA & NA & NA \\
\hline South-West & 468 & 17.7 & 3.0 & $1.5-5.3$ & NA & NA & NA & NA \\
\hline South-East & 668 & 25.3 & 2.7 & $1.4-4.7$ & NA & NA & NA & NA \\
\hline $\begin{array}{l}\text { Low vaccination } \\
\text { coverage } \\
\text { municipalities }\end{array}$ & NA & NA & NA & NA & 570 & 100 & 2.9 & $1.4-6.3$ \\
\hline \multicolumn{9}{|l|}{ Ethnicity } \\
\hline Dutch & 2306 & 87.5 & 2.8 & $2.0-3.7$ & 555 & 97.4 & 3.0 & $1.4-6.5$ \\
\hline $\begin{array}{l}\text { Non-Dutch } \\
\text { Western }\end{array}$ & 159 & 6.0 & 2.0 & $0.6-7.1$ & 12 & 2.1 & 0.0 & NA \\
\hline Non-Western & 172 & 6.5 & 3.4 & $1.4-8.4$ & 3 & 0.5 & 0.0 & NA \\
\hline \multicolumn{9}{|l|}{ Educational level* } \\
\hline High & 1257 & 46.7 & 2.5 & $1.6-3.9$ & 173 & 30.7 & 2.3 & $0.5-9.4$ \\
\hline Middle & 883 & 34.2 & 3.5 & $2.0-6.2$ & 252 & 44.8 & 4.4 & $1.7-10.9$ \\
\hline Low & 442 & 17.1 & 2.2 & $1.0-5.0$ & 138 & 24.5 & 0.9 & $0.1-6.3$ \\
\hline \multicolumn{9}{|l|}{ Religion } \\
\hline No religion & 1329 & 54.5 & 2.9 & $1.9-4.4$ & 145 & 28.0 & 0.3 & $0.0-3.7$ \\
\hline Roman Catholic & 613 & 25.1 & 3.4 & $1.7-6.6$ & 13 & 2.5 & 0.0 & NA \\
\hline Other & 119 & 4.9 & 0.0 & NA & 14 & 2.7 & 0.0 & NA \\
\hline Protestant & 379 & 15.5 & 3.0 & $1.6-6.4$ & 346 & 66.8 & 3.7 & $1.5-8.8$ \\
\hline $\begin{array}{l}\text { Orthodox- } \\
\text { Reformed }\end{array}$ & 28 & 7.4 & 8.5 & $2.4-26.9$ & 102 & 29.5 & 7.4 & $1.8-26.8$ \\
\hline Other & 351 & 92.6 & 2.6 & $1.0-6.5$ & 244 & 70.5 & 2.2 & $0.9-5.3$ \\
\hline
\end{tabular}

NA, Not applicable.

* Maternal educational level was used for participants $<15$ years of age

Missing: in the national sample: (maternal) educational level=55, religion $=197$; in the low vaccination coverage sample: (maternal) educational level=7, religion: 52 .

which anosmia/ageusia (53\%) was most discriminative as compared to the seronegative participants $(4 \%, \mathrm{p}<0.0001)$ (table 2). Symptoms were more common in women, except for anosmia/ageusia, cough and irritable/confusion. Almost $75 \%$ of the seropositive participants met the COVID-19 case definition of fever and/or cough and/or dyspnoea, which improved to $80 \%$ when anosmia/ageusia was included -while remaining $36 \%$ in those seronegative. GMC was significantly higher among seropositive persons with fever vs without ( 48.2 vs $11.6 \mathrm{AU} / \mathrm{mL}, \mathrm{p}=0.01)$, and with dyspnoea vs without (78.6 vs $13.5 \mathrm{AU} / \mathrm{mL}, \mathrm{p}=0.04)$. 
Table 2 COVID-19-related symptoms since the start of the epidemic among all participants in the PICO-study reporting symptoms $(n=3147)$, first round of inclusion

\begin{tabular}{|c|c|c|c|c|c|c|c|}
\hline & \multicolumn{2}{|c|}{$\begin{array}{l}\text { SARS-CoV-2 } \\
\text { seronegative } \\
\mathrm{n}=3073 \\
\end{array}$} & \multicolumn{2}{|c|}{$\begin{array}{l}\text { SARS-CoV-2 } \\
\text { seropositive } \\
\mathrm{n}=74 \\
\end{array}$} & \multicolumn{2}{|c|}{$\begin{array}{l}\text { Total } \\
\mathrm{n}=3147\end{array}$} & \multirow[b]{2}{*}{$P$ value* } \\
\hline & $\mathbf{n}$ & $\%$ & $\mathrm{n}$ & $\%$ & n & $\%$ & \\
\hline \multicolumn{7}{|c|}{ Meets COVID-19 case definition } & $<0.0001$ \\
\hline Yes & 1096 & 35.7 & 55 & 74.3 & 1151 & 36.6 & \\
\hline No & 1977 & 64.3 & 14 & 25.7 & 1996 & 63.4 & \\
\hline \multicolumn{7}{|c|}{$\begin{array}{l}\text { Meets COVID-19 case definition, and self-reported to have } \\
\text { had anosmia and/or ageusia }\end{array}$} & $<0.0001$ \\
\hline Yes & 1113 & 36.2 & 59 & 79.7 & 1172 & 37.2 & \\
\hline No & 1960 & 63.8 & 15 & 20.3 & 1975 & 62.8 & \\
\hline \multicolumn{7}{|c|}{ Developed symptoms since the start of the epidemic } & $<0.0001$ \\
\hline Yes & 1903 & 61.9 & 69 & 93.2 & 1972 & 62.7 & \\
\hline No & 1170 & 38.1 & 5 & 6.8 & 1175 & 37.3 & \\
\hline $\begin{array}{l}\text { General symptoms } \\
\text { (one or more) }\end{array}$ & 1350 & 43.9 & 62 & 83.8 & 1412 & 44.9 & $<0.0001$ \\
\hline Fever & 361 & 11.8 & 32 & 43.2 & 393 & 12.5 & $<0.0001$ \\
\hline General malaise & 332 & 10.8 & 34 & 46.0 & 366 & 11.6 & $<0.0001$ \\
\hline Headache & 1001 & 32.6 & 48 & 64.9 & 1049 & 33.3 & $<0.0001$ \\
\hline Irritable/confused & 232 & 7.6 & 17 & 23.0 & 249 & 7.9 & $<0.0001$ \\
\hline Muscle ache & 312 & 10.5 & 22 & 29.7 & 334 & 10.6 & $<0.0001$ \\
\hline Arthralgia & 497 & 16.2 & 42 & 56.8 & 539 & 17.1 & $<0.0001$ \\
\hline $\begin{array}{l}\text { Anosmia and/or } \\
\text { ageusia }\end{array}$ & 111 & 3.6 & 39 & 52.7 & 150 & 4.8 & $<0.0001$ \\
\hline $\begin{array}{l}\text { Respiratory symptoms } \\
\text { (one or more) }\end{array}$ & 1622 & 52.8 & 64 & 86.5 & 1686 & 53.6 & $<0.0001$ \\
\hline Cough & 905 & 29.5 & 45 & 60.8 & 950 & 30.2 & $<0.0001$ \\
\hline Sore throat & 798 & 26.0 & 33 & 44.6 & 831 & 26.4 & 0.0003 \\
\hline Runny nose & 1128 & 36.7 & 45 & 60.8 & 1173 & 37.3 & $<0.0001$ \\
\hline $\begin{array}{l}\text { Solely a runny nose \& } \\
\text { hay fever }\end{array}$ & 22 & 0.7 & 1 & 1.4 & 23 & 0.7 & $0.42 \dagger$ \\
\hline Dyspnoea & 251 & 8.2 & 13 & 17.6 & 264 & 8.4 & 0.004 \\
\hline $\begin{array}{l}\text { Gastrointestinal } \\
\text { symptoms (one or more) }\end{array}$ & 668 & 21.7 & 32 & 43.2 & 700 & 22.2 & $<0.0001$ \\
\hline Diarrhoea & 388 & 12.6 & 18 & 24.3 & 406 & 12.9 & 0.003 \\
\hline Nausea/vomiting & 207 & 6.7 & 13 & 17.6 & 220 & 7.0 & 0.0003 \\
\hline Stomach ache & 364 & 11.9 & 13 & 17.6 & 377 & 12.0 & 0.13 \\
\hline
\end{tabular}

${ }^{*} p$ values were calculated with Pearson's $\chi^{2}$ Test, unless depicted otherwise.

tp value was calculated with Fisher's Exact Test.

Missing values for all symptoms: 60 .

\section{Seroprevalence estimates}

Overall weighted seroprevalence in the NS was 2.8\% (95\% CI 2.1 to 3.7), did not differ between sexes or ethnic backgrounds (table 1), and was not higher among healthcare workers $(2.7 \%$ vs nonhealthcare workers $2.5 \%$ ). Seroprevalence was lowest in the northern region (1.3\%) and highest in the mid-west (4.0\%). Estimates were lowest in children — gradually increasing from below $1 \%$ at age 2 years to $3 \%$ at 17 years-was highest in age group $18-39$ years (4.9\%) and ranged between 2 and $4 \%$ up to 90 years of age (figure 2). In both samples, seroprevalence was highest in Orthodox-Reformed Protestants (>7\%) (table 1). Online supple ment figure S1B displays the distribution of IgG concentrations for all participants by age, and online supplemental figure $S 2$ shows the seroprevalence smoothed by age in the LVC.

\section{Risk factors for SARS-CoV-2 seropositivity}

Variables that were associated with SARS-CoV-2 seropositivity in univariable analyses included age group, Orthodox-Reformed

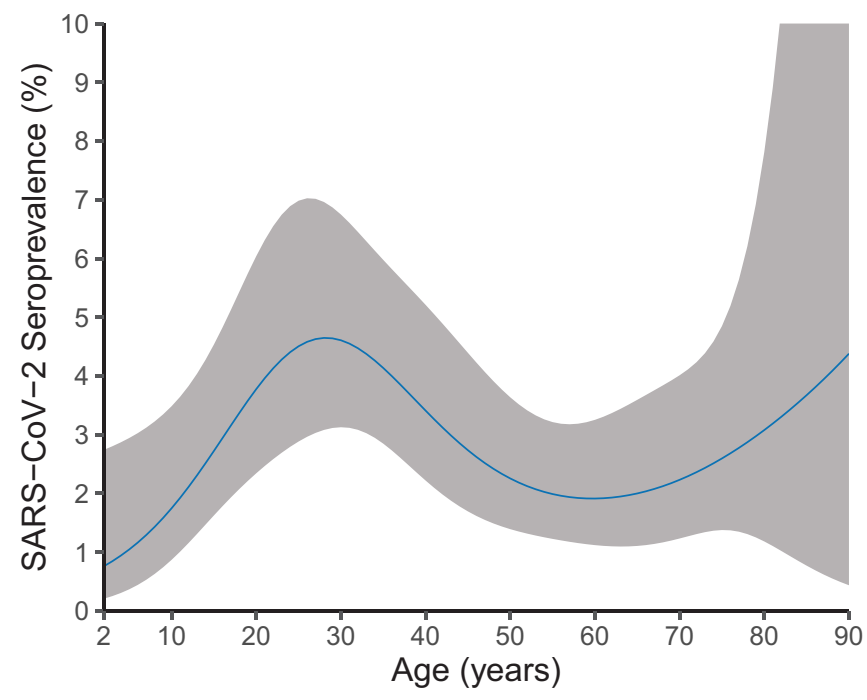

Figure 2 Smooth age-specific SARS-CoV-2 seroprevalence in the general population of the Netherlands, beginning of April 2020.

Protestant, had been in contact with a COVID-19 case, use of immunosuppressants, and antibiotic/antiviral medication in the last month (table 3). In multivariable analysis, substantial higher odds were observed for those who took immunosuppressants the last month, were Orthodox-Reformed Protestant, had been in contact with a COVID-19 confirmed case, and from age groups 18-24 and 25-39 years (compared to 2-12 years).

\section{DISCUSSION}

Here, we have estimated the seroprevalence of SARS-CoV-2-specific antibodies and identified risk factors for seropositivity in the general population of the Netherlands during the first epidemic wave in April 2020. Although overall seroprevalence was still low at this phase, important risk factors for seropositivity could be identified, including adults aged 18-39 years, persons using immunosuppressants, and Orthodox-Reformed Protestants. These data can guide future interventions, including strategies for vaccination, believed to be a realistic solution to overcome this pandemic.

This PICO-study revealed that $2.8 \%$ (95\% CI 2.1 to 3.7) of the Dutch population had detectable SARS-CoV-2-specific serum IgG antibodies, suggesting that almost half a million inhabitants (of in total $17423981^{17}$ ) were infected (487 871 (95\% CI 365904 to 644 687)) in mid-March, 2020 (taking into account the median time to seroconvert ${ }^{18}$ ). Several seropositive participants reported to have had COVID-19-related symptoms back in mid-February, suggesting the virus circulated in our country at the beginning of February already. Our overall estimate is in line with preliminary results from another study conducted in the Netherlands in the beginning of April which found 2.7\% to be seropositive, although this study was performed in healthy blood donors aged 18-79 years. ${ }^{19}$ Worldwide, various seroprevalence studies are ongoing. A large nationwide study in Spain showed that around 5\% (ranging between $3.7 \%$ and $6.2 \%$ ) was seropositive, indicating that only a small proportion of the population had been infected in one of the hardest hit countries in Europe. Current studies in literature mostly cover COVID-19 hotspots or specific regions-with possibly bias in selection of participants and/or smaller age-ranges-with rates ranging between 1-7\% in April (eg, in Los Angeles County (CA, USA) ${ }^{20}$ or ten other sites in the USA, ${ }^{21}$ Geneva (Switzerland), ${ }^{22}$ and Luxembourg ${ }^{23}$ ). 
Table 3 Risk factor analysis for SARS-CoV-2 seropositivity among all participants ( $n=3100$; full case analysis) in the PICO-study, first round of inclusion

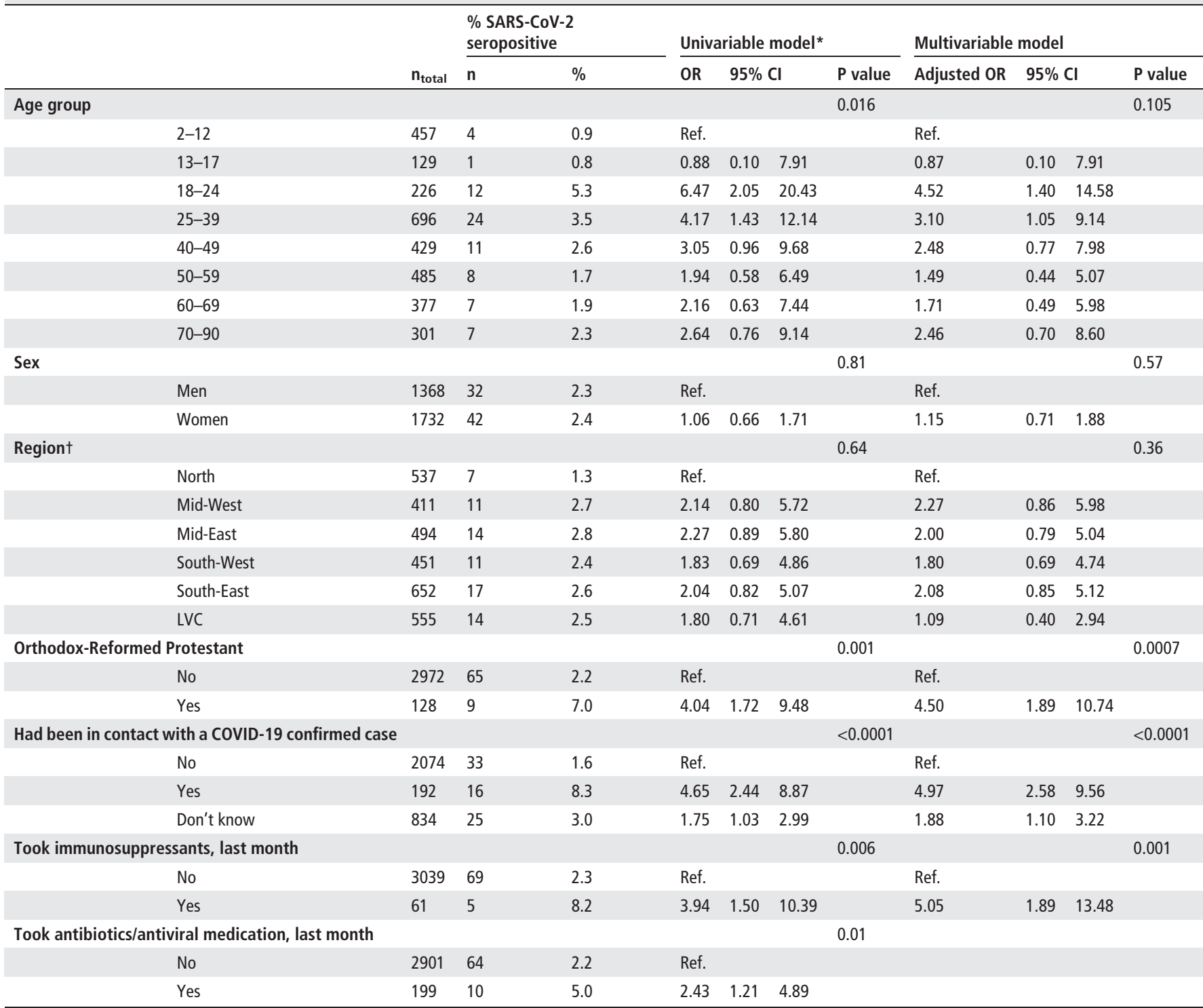

*Variables that were not associated with SARS-CoV-2 seropositivity in univariable analyses (ie, $\mathrm{p} \geq 0.10$ )—or that were not controlled for—included: ethnic background, (maternal) educational level, household size, (parent with a) contact profession, healthcare worker, number of persons contacted yesterday, working from home (normally and in the last week (during lockdown)), comorbidities (combining chronic lung disease, diabetes, history of malignancy, immunodeficiency, cardio-vascular disease, kidney disease), and use of blood pressure medication, immunosuppressants, statins and antivirals/antibiotics in the last month.

tRegion North comprised provinces Groningen, Friesland, Drenthe and Overijssel, region Mid-West provinces Noord-Holland and Flevoland, region Mid-West provinces Utrecht and Gelderland, region South-West provinces Zuid-Holland and Zeeland, and region South-East provinces Noord-Brabant and Limburg.

Cl, Confidence interval; LVC, Low vaccination coverage municipalities; OR, Odd ratio; Ref., Reference category.

Estimates also very much depend on test performances. Particularly, when seroprevalence is relatively low, specificity of the assay should approach near 100\% to diminish false-positive results and minimise overestimation. Although we cannot ruleout false-positive samples completely, our assay was validated using a broad range of positive and negative SARS-CoV-2 samples; PICO-samples were cross-linked to pre-pandemic concentration; and bias correction for test performance was applied to represent most accurate estimates. In addition, future studies should establish whether epidemiologically dominant genetic changes in the spike protein of SARS-CoV-2 influence binding to spike S1 used in our and other assays.

Seroprevalence was highest in adults aged 18-39 years, which is in line with the serosurvey among blood donors in the
Netherlands, but contrary to the low incidence rate as reported in Dutch surveillance, caused by restrictive testing of risk groups and healthcare workers at the beginning of the epidemic, primarily identifying severe cases. ${ }^{3}{ }^{19}$ The elevation in these younger adults may be explained by increased social contacts typical for this age group, in addition to specific social activities in February, such as skiing holidays in the Alps (from where the virus disseminated quickly across Europe), or carnival festivities in the Netherlands (ie, multiple superspreading events primarily in the mid and Southern part, explaining local elevation in seroprevalence). In correspondence with other nationwide studies ${ }^{89}$ and reports from the Dutch government, ${ }^{3} 24$ seroprevalence was lowest in children. Although some rare events of paediatric inflammatory multisystem syndrome have been reported, this group seems 
to be at decreased risk for developing (severe) COVID-19 in general, which may be explained by less severe infection possibly resulting in a limited humoral response. ${ }^{25}{ }^{26}$ Further, significantly higher odds for seropositivity were seen in Orthodox-Reformed Protestants. This community lives socio-geographically clustered in the Netherlands, that is, work, school, leisure and church are intertwined heavily. As observed in other countries, particularly frequent attendance of church with close distance to others, including singing activities, might have fuelled the spread of SARS-CoV-2 within this community in the beginning of the epidemic. ${ }^{11} 12$ Whereas the comorbidities with possible increased risk of severe COVID-19 were not associated with seropositivity in this study, immunosuppressants use did display higher odds (note: we did not have information of specific drugs). Recent data indicate that immunosuppressive treatment is not associated with worse COVID-19 outcomes, ${ }^{27} 28$ yet continued surveillance is warranted as these patients might be more prone to (future) infection, for instance due to a possible attenuated humoral immune response. ${ }^{29}$

The majority of seropositive participants exhibited $\geq 1$ symptom(s), mostly general and respiratory. A recent metaanalysis found a pooled asymptomatic proportion of $16 \%,{ }^{5}$ hence the observed overall fraction in the present study (7\%) might be a conservative estimate as the self-reported symptoms could have been due to other reasons or circulating pathogens along the recalled period (ie, $62 \%$ of the seronegative participants reported symptoms too). The asymptomatic proportion might be different across ages ${ }^{5}$ and should be explored further along with elucidating the overall contribution of asymptomatic transmission via well-designed contact-tracing studies. Interestingly, clinical studies have observed anosmia/ageusia to be associated with SARS-CoV-2 infection, and this notion is supported here at a population-based level. ${ }^{30}$ In the pandemic context, sudden onset of anosmia/ageusia seems to be a useful surveillance tool, which can contribute to early disease recognition and minimise transmission by rapid self-isolation.

This study has some limitations. First, although half of the total municipalities in the Netherlands were included, some COVID19 hotspots might be missed due to the study design. Second, our study population consisted of more Dutch (88\%) than non-Dutch persons and relative more healthcare workers $(20 \%)$ when compared to the general population ( $76 \%$ and $14 \%$, respectively). ${ }^{17}$ Healthcare workers in the Netherlands do not seem to have had a higher likelihood of infection, and transmission seems to have taken place mostly in household settings. ${ }^{31}$ Although selectivity in response was minimised by weighting our study sample on a set of sociodemographic characters to match the Dutch population, seroprevalence might still be slightly influenced. Third, some potential determinants for seropositivity could have been missed as we might have been underpowered to detect small differences given the low prevalence in this phase, or because these questions had not been included in the questionnaire (as it was designed in the very beginning of the epidemic). Finally, at this stage the proportion of infected individuals that fail to show detectable seroconversion is unknown, potentially leading to underestimation of the percentage of infected persons.

To conclude, we estimated that $2.8 \%$ of the Dutch inhabitants, that is, nearly half a million, were infected with SARS-CoV-2 amidst the first epidemic wave in the beginning of April 2020. This is in striking contrast with the 30 -fold lower number of reported cases (of approximately 15000$)^{3}$, and underlines the importance of seroepidemiological studies to estimate the true pandemic size. The proportion of persons still susceptible to SARS-CoV-2 is high and IFR is substantial. ${ }^{4}$ Globally, nationwide seroepidemiological studies are urgently needed for better understanding of related risk factors, viral spread, and measures applied to mitigate dissemination. ${ }^{7}$ The prospective nature of our study will enable us to gain key insights on the duration and quality of antibody responses in infected persons, and hence possible protection of disease by antibodies. ${ }^{6}$ Serosurveys will thus play a major role in guiding future interventions, such as strategies for vaccination (of risk groups), since even when vaccines become available, initial vaccine availability will be limited.

\section{What is already known on this topic}

- Reported COVID-19 cases worldwide are an underestimation of the true magnitude of the pandemic as the scope of undetected cases remains largely unknown.

- Various symptoms and risk factors have been identified in patients seeking medical advice, however, these may not be representative for infections in the general population.

- Seroepidemiological studies in outbreak settings have been performed, however, studies on a nationwide level covering all ages remain limited.

\section{What this study adds}

- This nationwide seroepidemiological study covering all ages reveals that $2.8 \%$ of the Dutch population had been infected with SARS-CoV-2 at the beginning of April 2020, that is, 30 times higher than the official cases reported, leaving a large proportion of the population still susceptible for infection.

- The highest seroprevalence was observed in young adults from 18 to 39 years of age and lowest in children aged 2 to 17 years, indicating marginal SARS-CoV-2 infections among children in general.

- Persons taking immunosuppressants as well as those from the Orthodox-Reformed Protestant community had over four times higher odds of being seropositive compared to others.

- The extend of the spread of SARS-CoV-2 and the risk groups identified here, can inform monitoring strategies and guide future interventions internationally.

\footnotetext{
Acknowledgements First of all, we gratefully acknowledge the participants of the PICO-study. Secondly, this study would not have been possible without the instrumental contribution of colleagues from the National Institute of Public Health and Environment (RIVM), Bilthoven, the Netherlands, more specially the department of Immunology of Infectious Diseases and Vaccines, regarding logistics and/or laboratory analyses (Marjan Bogaard-van Maurik, Annemarie Buisman, Pieter van Gageldonk, Hinke ten Hulscher-van Overbeek, Petra Jochemsen, Deborah Kleijne, Jessica Loch, Marjan Kuijer, Milou Ohm, Hella Pasmans, Lia de Rond, Debbie van Rooijen, Liza Tymchenko, Esther van Woudenbergh, and Mary-lene de Zeeuw-Brouwer), the Epidemiology and Surveillance department concerning logistics (Francoise van Heiningen, Alies van Lier, Jeanet Kemmeren, Joske Hoes, Maarten Immink, Marit Middeldorp, Christiaan Oostdijk, Ilse Schinkel-Gordijn, Yolanda van Weert, and Anneke Westerhof), methodological insights (Hendriek Boshuizen, Susan Hahné, Scott McDonald, Rianne van Gageldonk-Lafeber, Jan van de Kassteele, and Maarten Schipper) and manuscript reviewing (Susan van den Hof, and Don Klinkenberg), department of IT and Communication for help with the invitations (Luppo de Vries, Daphne Gijselaar, and Maaike Mathu), student interns for additional support (Stijn Andeweg for creating online supplemental figures $1 \mathrm{~A}$ and $1 \mathrm{~B}$; Janine Wolf, Natasha Kaagman, and Demi Wagenaar for logistics; and Lisette van Cooten for data entry of paper questionnaires), and Sidekick-IT, Breda, the Netherlands, regarding data flow (Tim de Hoog). This study was funded by the ministry of Health, Welfare and Sports (VWS), the Netherlands.
} 
Map disclaimer The depiction of boundaries on the map(s) in this article does not imply the expression of any opinion whatsoever on the part of BMJ (or any member of its group) concerning the legal status of any country, territory, jurisdiction or area or of its authorities. The map(s) are provided without any warranty of any kind, either express or implied.

Contributors RV wrote the manuscript. FvK, HdM, PK, LM, RV, RvB, and AWM conceived the study. RV and LM conducted the epidemiological data analyses, MvB provided code for the GAM model and statistical advise, and HdM supervised the analyses. JVV and GS supervised the logistics and performed - among other technicians mentioned in the acknowledgments - the laboratory analyses. RS, RvB, and $\mathrm{GdH}$ designed the laboratory assay and supervised the laboratory analyses. LM, RV, KH, AWM, GS, GdH, and JV processed the data. FvK was principal investigator of the study. All authors contributed to the interpretation of data, and read, edited and approved the final manuscript.

Funding This study was funded by the Ministry of Health, Welfare and Sports (VWS), the Netherlands. RV is a PhD-student and epidemiologist at the National Institute for Public Health and the Environment (RIVM). The views expressed are those of the authors and not necessarily those of VWS or the RIVM. The funder played no role in study design; in the collection, analysis, and interpretation of data; in the writing of the report; or in the decision to submit the paper for publication. The corresponding author (FvdK) had full access to all the data in the study and had final responsibility for the decision to submit for publication.

Competing interests None declared.

Patient consent for publication Not required.

Ethics approval This study was approved by the Medical Ethics Committee MEC-U, the Netherlands (Clinical Trial Registration NTR8473), and is available.

Provenance and peer review Not commissioned; externally peer reviewed.

Data availability statement Our data are accessible to researchers upon reasonable request for data sharing to the corresponding author

Dissemination declaration Key study results will be disseminated to the participants on a population-based level (ie, not on an individual level) during the course of the study.

Supplemental material This content has been supplied by the author(s). It has not been vetted by BMJ Publishing Group Limited (BMJ) and may not have been peerreviewed. Any opinions or recommendations discussed are solely those of the author(s) and are not endorsed by BMJ. BMJ disclaims all liability and responsibility arising from any reliance placed on the content. Where the content includes any translated material, BMJ does not warrant the accuracy and reliability of the translations (including but not limited to local regulations, clinical guidelines, terminology, drug names and drug dosages), and is not responsible for any error and/ or omissions arising from translation and adaptation or otherwise.

Open access This is an open access article distributed in accordance with the Creative Commons Attribution Non Commercial (CC BY-NC 4.0) license, which permits others to distribute, remix, adapt, build upon this work non-commercially, and license their derivative works on different terms, provided the original work is properly cited, appropriate credit is given, any changes made indicated, and the use is noncommercial. See: http://creativecommons.org/licenses/by-nc/4.0/.

ORCID iDs

Eric R A Vos http://orcid.org/0000-0001-9124-5836

Gerco den Hartog http://orcid.org/0000-0002-2103-6315

\section{REFERENCES}

1 John Hopkins University. COVID-19 dashboard by the center for systems science and engineering. 2020. Available https://gisanddata.maps.arcgis.com/apps/opsdash board/index.htm/\#/bda7594740fd40299423467b48e9ecf6 (accessed 2 Jul 2020).

2 World Health Organization (WHO). WHO Director-General's opening remarks at the media briefing on COVID-19-11 March 2020. 2020. Available https://www.who.int/dg/ speeches/detail/who-director-general-s-opening-remarks-at-the-media-briefing-oncovid-19-11-march-2020 (accessed 12 May 2020).

3 National Institute for Public Health and the Environment (RIVM). Daily situational report of COVID-19 in the Netherlands - July 2, 2020 (in Dutch). Bilthoven: RIVM, 2020.

4 Verity R, Okell LC, Dorigatti I, et al. Estimates of the severity of coronavirus disease 2019: a model-based analysis. Lancet Infect Dis 2020;20:669-77.
5 He J, Guo Y, Mao R, et al. Proportion of asymptomatic coronavirus disease 2019: a systematic review and meta-analysis. J Med Virol 2020

6 Altmann DM, Douek DC, Boyton RJ. What policy makers need to know about COVID-19 protective immunity. Lancet 2020;395:1527-9.

7 Goudsmit J. The paramount importance of serological surveys of SARS-CoV-2 infection and immunity. Eur J Epidemiol 2020;35:331-3.

8 Pollán M, Pérez-Gómez B, Pastor-Barriuso R, et al. Prevalence of SARS-CoV-2 in Spain (ENE-COVID): a nationwide, population-based seroepidemiological study. Lancet.

9 Gudbjartsson DF, Helgason A, Jonsson H, et al. Spread of SARS-CoV-2 in the icelandic population. N Engl J Med 2020;382:2302-15.

10 World Health Organization (WHO). Coronavirus disease (COVID-19) technical guidance: the Unity Studies: early investigations protocols. 2020. Available https://www. who.int/emergencies/diseases/novel-coronavirus-2019/technical-guidance/earlyinvestigations (accessed 20 Mar 2020)

11 James A, Eagle L, Phillips C, et al. High COVID-19 attack rate among attendees at events at a Church - Arkansas, March 2020. MMWR Morb Mortal Wkly Rep 2020;69:632-5.

12 Yong SEF, Anderson DE, Wei WE, et al. Connecting clusters of COVID-19: an epidemiological and serological investigation. Lancet Infect Dis 2020;20:809-15.

13 Verberk JDM, Vos RA, Mollema L, et al. Third national biobank for population-based seroprevalence studies in the Netherlands, including the Caribbean Netherlands. BMC Infect Dis 2019;19:470.

14 den Hartog G, Schepp RM, Kuijer M, et al. SARS-CoV-2: specific antibody detection for seroepidemiology: a multiplex analysis approach accounting for accurate seroprevalence. J Infect Dis 2020;222:1452-61.

15 Rogan WJ, Gladen B. Estimating prevalence from the results of a screening test. Am J Epidemiol 1978;107:71-6

16 Wood SN. Fast stable restricted maximum likelihood and marginal likelihood estimation of semiparametric generalized linear models. J R Stat Soc Series B Stat Methodol 2011;73:3-36

17 Statistics Netherlands (CBS). Statline database 2020 Available https://opendata.cbs.nl/ statline/\#/CBS/en/ (accessed 20 May 2020)

18 Guo L, Ren L, Yang S, et al. Profiling early humoral response to diagnose novel coronavirus disease (COVID-19). Clin Infect Dis 2020;

19 Slot E, Hogema BM, Reusken CBEM, et al. Herd immunity is not a realistic exit strategy during a COVID-19 outbreak. Res Square 2020;preprint.

20 Sood N, Simon P, Ebner P, et al. Seroprevalence of SARS-CoV-2: specific antibodies among adults in Los Angeles County, California, on April 10-11, 2020. JAMA 2020;323:2425-7.

21 Havers FP, Reed C, Lim T, et al. Seroprevalence of antibodies to SARS-CoV- 2 in 10 Sites in the United States, March 23-May 12, 2020. JAMA Intern Med 2020.

22 Stringhini S, Wisniak A, Piumatti G, et al. Seroprevalence of anti-SARS-CoV-2 lgG antibodies in Geneva, Switzerland (SEROCoV-POP): a population-based study. Lancet 2020:396:313-9.

23 Snoeck CJ, Vaillant M, Abdelrahman T, et al. Prevalence of SARS-CoV-2 infection in the Luxembourgish population: the CON-VINCE study. medRxiv 2020; (preprint):2020.05.11.20092916

24 van der Hoek W, Backer JA, Bodewes R, et al. The role of children in the transmission of SARS-CoV-2. Ned Tijdschr Geneeskd 2020;164.

25 She J, Liu L, Liu W. COVID-19 epidemic: disease characteristics in children. J Med Virol 2020:92:747-54.

26 Zhang J, Litvinova M, Liang Y, et al. Changes in contact patterns shape the dynamics of the COVID-19 outbreak in China. Science 2020.

27 Fredi M, Cavazzana I, Moschetti L, et al. COVID-19 in patients with rheumatic diseases in northern Italy: a single-centre observational and case control study. Lancet Rheumatol.

28 Thng ZX, De Smet MD, Lee CS, et al. COVID-19 and immunosuppression: a review of current clinical experiences and implications for ophthalmology patients taking immunosuppressive drugs. Br J Ophthalmol 2020;bjophthalmol2020-316586

29 Kronbichler A, Gauckler P, Windpessl M, et al. COVID-19: implications for immunosuppression in kidney disease and transplantation. Nat Rev Nephrol 2020;16:365-7.

30 Tostmann A, Bradley J, Bousema T, et al. Strong associations and moderate predictive value of early symptoms for SARS-CoV-2 test positivity among healthcare workers, the Netherlands, March 2020. Euro Surveill 2020;25:16.

31 Sikkema RS, Pas SD, Nieuwenhuijse DF, et al. COVID-19 in health-care workers in three hospitals in the south of the Netherlands: a cross-sectional study. Lancet Infect Dis. 